\title{
NUTRITIONAL MANAGEMENT IN CHILD DIARRHEA: AN EVALUATION OF AWARENESS IN GENERAL POPULATION FROM DOBROGEA REGION
}

\section{Diacăn Adrian1, Maurodin Mihaela², Mihai Larisia ${ }^{3}$, Gambrea Simona Glaudia ${ }^{12}$}

${ }^{1}$ Faculty of Medicine, „Ovidius” University, Constanta, Romania

${ }^{2}$ Clinical Infectious Diseases Hospital of Constanta, Romania

${ }^{3}$ Emergency County Clinical Hospital of Constanta "Sf. Ap. Andrei”, Constanta, Romania

Mihai Larisia

Emergency County Clinical Hospital of Constanta "Sf. Ap. Andrei", 145, Tomis Avenue, 900591, Constanta, Romania email:larisiamihai@yahoo.com

\begin{abstract}
Diet has a major role in the treatment of acute diarrhea in children, along with a minimal drug therapy, but not necessarily using antimicrobials. Children can successfully pas a diarrheal episode with diet and symptomatic treatment.

It is important to know how to properly choose foods to introduce in ill children diet. There is a lack of statistical data in our region regarding dietary treatment in child diarrhea. This study was realized by completing a questionnaire regrading nutritional management in children with diarrhea. 110 persons from Dobrogea region completed this questionnaire. We analyzes demographic and clinical issues, people preferences in choosing different foods appropriate to this pathology and minimal knowledge about medication.

Our results evidenced that general population knowledges regarding nutritional management of acute diarrheal disease in children and infants are appreciable. Foods like rice, toast, applesauce/baked apple, mint/figs/bilberry leaves teas, vegetables soup, bananas were found among people preferences, proving appropriate information. Antimicrobial drugs misusage is not reported, 83 out of 110 people avoiding them.
\end{abstract}

Keywords: nutritional management; diarrhea, infants, children

\section{INTRODUGTION}

Globally, acute diarrheal disease is an important cause of malnutrition, morbidity and mortality among infants and children. In developing countries, children suffer episodes of acute diarrhea in 35 to 70 days/year (1). Besides dehydration and electrolyte imbalance, acute diarrhea has repercussions on nutritional status of the children.

In developed countries, children's nutritional background is sufficient to help override a diarrheal episode; the more good quality foods with high nutritional index are available, the less malnutrition and other consequences are expected to appear. On the other hand, in developing countries, more than $30 \%$ of children can become malnourished. In this situation, even a mild diarrheal episode can disturb their nutritional balance requiring prompt intervention to prevent its consequences (2).

\section{DIETARY IN CHILD WITH DIARRHEA}

In the past, acute diarrheal diseases rivaled with respiratory illnesses for the first place in child mortality among children aged $0-1$ year (3). Due to the continuous improvement of living conditions and the advancement in medical research such as understanding of etiopathogenetic mechanisms, 
the establishment of adequate treatment plans, medical education of general population, acute diarrheal diseases now occupy fourth place as cause of child mortality in different places of the world (4).

Therapeutic guidelines recommend maintaining a relatively normal feeding throughout the recovery of a diarrheal episode. Expected benefits may vary depending on nutritional values of the foods given to children, which can be enhanced with various supplements for a quicker recovery. An ideal diet should be able to provide the nourishment needed for passing a diarrheal episode, thus supplementing basic requirements for normal child growth and development (5). Choosing proper foods, proper way of cooking and right frequency of feedings depends on the child age, his eating habits and state of health. Special attention must be paid on the foods used: the quantity and quality of their nutrients, the quality of the carbohydrates and fats, biological values of the proteins and, if possible, their osmolarity. The need of specific foods must be considered as well $(6,7)$.

As for breastfed infants, their feeding should be continued during recovery from a diarrheal episode. Eutrophic infants, aged under 6 months, can rely on a breast milk only diet since it is suitable for them and can correct by itself all nutritional deficiencies that appear in diarrhea. Certain additions to this diet are recommended for infants aged over 6 months, using foods that are well tolerated by them $(8,9)$.

A study performed by Hoque and Binder, regarding the importance of Zinc in children's diet, revealed that this vital mineral helped in the treatment of acute diarrhea in children younger than 5 years (10).

Oral rehydration and prompt refeeding are important in treating an acute diarrheal episode $(11,12)$. B.R.A.T. diet is often prescribed and is composed of following foods: Bananas, Rice, Applesauce, Toast and Tea.

This diet imply the combination of certain foods containing dietary fibers with low nutritional status; however, these foods are supposed to be well tolerated by children's gastro-intestinal tract, during diarrheal episodes. BRAT diet is frequently used as a short-term solution for a good nutritional management (13).

\section{MATERIAL AND METHOD}

The study was based on the elaboration of a questionnaire shared to 110 people, located in Dobrogea region (Constanta and Tulcea counties), Romania, between July 2018 - April 2019. Google Forms platform was used to collect and analyze the results.

\section{RESULTS AND DISCUSSION}

Demographic data revealed that women represents the majority of the interviewees, 93 out of $110(84.5 \%), 87$ out of $110(79.1 \%)$ are caucasians and the predominant group age, of 2530 years, contains 41 people $(37.3 \%)$. Regarding level of education, 54 out of 110 people (49.1\%) went to high school or graduated high-school.

Given that diarrheal diseases have high frequency among children and infants, people were asked about their child medical history. 107 out of $110(97.3 \%)$ of them confirmed at least one diarrheal episode. The addressability to the general practitioner may be improved, 72 out of 110 went to the doctor as first symptoms appeared on their child. From those who refused a medical examination, 52.6\% (20 people out of 38) did not considered it necessary in their child case. When asked about the importance of dietary in the treatment of child diarrhea, 78 out of 110 (70.90\%) find it important for a proper treatment of the disease and only 3 persons $(2.72 \%)$ claimed it is not.

A. Foods. Proper nutritional management of diarrheal disease imply good knowledges about foods and their nutritional content. This study reveals that people know what foods to choose for feeding their ill infant/child. Foods like rice (chosen by $70 \%$ ), toast $(67.27 \%$ ), applesauce/ baked apple (50.90\%), mint/figs/bilberry leaves teas $(43.63 \%)$, vegetables soup $(43.63 \%)$, and bananas $(40.90 \%)$, grilled/boiled meat like chicken breast or beef $(40.90 \%)$, boiled carrots $(40 \%)$ were in top of preferences of people. All these represents proper choices $(7,14,15)$.

Figure 1 shows foods in the order of people preferences for adding them in children's diet. 


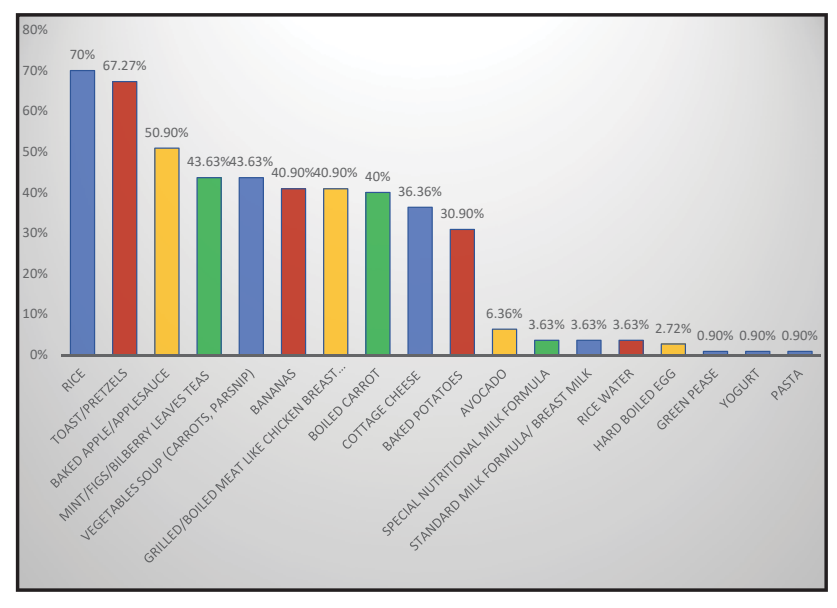

Figure 1 - people's food selections for their children diet

Bananas and rice are known for their role in the improvement of health status of children with diarrhea. Bananas contain amylase resistant starch, which is capable of generating short-chain fatty acids in the colon. This generation improves absorption of water and electrolytes from the content of bowels, thus reducing the volume of stool and increasing it's consistency (15). Rice may contain substances that can induce antisecretory effects in the intestinal mucosa (16).

There is a study (17) performed by Rabbani et al in 2001, in Bangladesh, on 62 boys aged 5 months to 1 year old, comparing recovery outcomes of children fed with rice only diet and those fed with rice mixed with cooked green bananas or pectin. They noticed that children fed with mixture of rice and bananas/pectin had better improvements of their recovery from diarrhea than those receiving rice only diet. On the third day of the observation, $55 \%-59 \%$ of those fed with rice and bananas/pectin mixture did not had diarrhea anymore, comparing to $15 \%$ fed with rice only.

Sixty-seven out of one hundred ten respondents $(60.90 \%)$ claimed diet had an important role in the improvement of their child symptoms; 21 people $(19.09 \%)$ reported a complete recovery from diarrhea, while tree out of one hundred ten claimed it did not helped at all.

B. Drug therapy. The survey contains a section regarding minimal knowledge about drugs used in treatment of child diarrhea. In order to prevent confusions about therapeutic classes or active ingredients of drugs among people, their brand/commercial names were used to identify them.

Anti-diarrheal medication, such as Racecadrotilum (36.36\%) or Diosmectitis (29.29\%) are preferred; 24 out 110 (21.81\%) choose not to use any anti-diarrheal medication whatsoever.

Probiotic therapy, based on Lacobacillus casei $(20 \%)$, or Lactobacillus acidophilus $(16.36 \%)$ and others $(32.74 \%)$ were administrated, while 34 out of 110 respondents $(30.90 \%)$ choose not to use them. A metaanalysis revealed that Lactobacillus spp. can be beneficial in the treatment of acute infectious diarrhea (18), shortening the disease time. Furthermore, Lactobacillus spp. brought clinical improvements in cases of antibiotic-associated diarrhea $(19,20)$.

Symptomatic relief drugs are useful in preventing any further complications. Oral rehydration salts were used by 54 out of 110 (49.09\%), Metoclopramide, by 10 and Motilium, by 9 people. However, 40 out of 110 (36.36\%) decide not to administrate them.

Antimicrobial therapy was avoided by 83 out of $110(75.46 \%)$; a good result considering that only $10 \%$ to $20 \%$ of cases of child diarrhea are caused by bacteria.

\section{CONCIUSIONS}

General population knowledge regarding nutritional management of acute diarrheal disease in children and infants are appreciable. Foods like rice, toast, applesauce/baked apple, mint/figs/bilberry leaves teas, vegetables soup, bananas were found among people preferences, proving appropriate information.

Between interviewees, just $14.15 \%$ do not know or do not find important nutritional management in treatment of diarrheal episodes; in their case, some information were given as a cultivation.

Antimicrobial drugs misusage is not reported, $75.45 \%$ people from our study avoiding them.

\section{REFERENGES}

1. Black RE, Brown KH, Becker S, Yunus M. Longitudinal studies of infectious diseases 
and physical growth of children in rural Bangladesh. I. Patterns of morbidity. Am J Epidemiol. 1982 Mar;115(3):305-14.

2. Snyder JD, Merson MH. The magnitude of the global problem of acute diarrhoeal disease: a review of active surveillance data. Bull World Health Organ. 1982;60(4):60513.

3. Centers for disease Control and Prevention. Global Diarrhea Burden. CDC; 2015 [cited 2019]; Available from: https://www.cdc.gov/ healthywater/global/diarrhea-burden.html.

4. Ghasemi AA, Talebian A, Alavi NM, Mousavi GA. Knowledge of Mothers in Management of Diarrhea in Under-Five Children, in Kashan, Iran. Nursing and Midwifery Studies. 2013;1(3):158-62.

5. Turner JR. Intestinal mucosal barrier function in health and disease. Nat Rev Immunol. 2009 Nov;9(11):799-809.

6. Lutter CK, Mora JO, Habicht JP, Rasmussen KM, Robson DS, Sellers SG, et al. Nutritional supplementation: effects on child stunting because of diarrhea. Am J Clin Nutr. 1989 Jul;50(1):1-8.

7. Gaffey MF, Wazny K, Bassani DG, Bhutta ZA. Dietary management of childhood diarrhea in low- and middle-income countries: a systematic review. BMC Public Health. 2013;13 Suppl 3:S17.

8. Ballard O, Morrow AL. Human milk composition: nutrients and bioactive factors. Pediatr Clin North Am. 2013 Feb;60(1):4974.

9. Zugravu C, Nanu M, Moldovanu F, Arghir O, Mihai C, Otelea M, Cambrea SC. The Influence of Perinatal Education on Breastfeeding Decision and Duration. International Journal of Child Health and Nutrition. 2018:7(2) :74-81.

10. Hoque KM, Binder HJ. Zinc in the treatment of acute diarrhea: current status and assessment. Gastroenterology. 2006 Jun;130(7):2201-5.

11. Ntaba D. BRAT Diet: Axiom or Unsubstantiated Myth? Emergency Medicine News. 2004;26(13): 27.

12. Ramakrishna BS, Venkataraman S, Srinivasan P, Dash P, Young GP, Binder HJ. Amylase-resistant starch plus oral rehydration solution for cholera. $\mathrm{N}$ Engl $\mathrm{J}$ Med. 2000 Feb 3;342(5):308-13.

13. Duro D, Duggan C. The BRAT diet for acute diarrhea in children: Should it be used? Practical Gastroenterology. 2007;31:60-8.

14. Duggan C, Gannon J, Walker WA. Protective nutrients and functional foods for the gastrointestinal tract. Am J Clin Nutr. 2002 May;75(5):789-808.

15. Binder HJ, Mehta P. Short-chain fatty acids stimulate active sodium and chloride absorption in vitro in the rat distal colon. Gastroenterology. 1989 Apr;96(4):989-96.

16. Macleod RJ, Bennett HP, Hamilton JR. Inhibition of intestinal secretion by rice. Lancet. 1995 Jul 8;346(8967):90-2.

17. Rabbani GH, Teka T, Zaman B, Majid N, Khatun M, Fuchs GJ. Clinical studies in persistent diarrhea: dietary management with green banana or pectin in Bangladeshi children. Gastroenterology. 2001 Sep;121(3):554-60.

18. Szajewska H, Kotowska M, Mrukowicz JZ, Armanska M, Mikolajczyk W. Efficacy of Lactobacillus GG in prevention of nosocomial diarrhea in infants. J Pediatr. 2001 Mar;138(3):361-5.

19. D'Souza AL, Rajkumar C, Cooke J, Bulpitt CJ. Probiotics in prevention of antibiotic associated diarrhoea: meta-analysis. BMJ. 2002 Jun 8;324(7350):1361.

20. King CK, Glass R, Bresee JS, Duggan C. Managing acute gastroenteritis among children: oral rehydration, maintenance, and nutritional therapy. MMWR Recomm Rep. 2003 Nov 21;52(Rr-16):1-16. 